\title{
Estimativa do Potencial Energético de Resíduos Celulósicos de Fabricação de Papel
}

\section{Através de Análise Imediata ${ }^{1}$}

Italo Tadeu M. Ferreira ${ }^{2}$, Waldir Nagel Schirmer ${ }^{3}$, Gilmara de Oliveira Machado ${ }^{4}$, Matheus Vitor Diniz Gueri ${ }^{5}$

1 Aceito para publicação no $3^{\circ}$ Trimestre de 2014

2 Especialista em Processos na Ibema, Cia. Brasileira de Papel, ítalo.tadeu2010@ hotmail.com

3 Professor Dr. do Departamento de Engenharia Ambiental da Universidade Estadual do Centro- Oeste- UNIVENTRO, wanasch@ hotmail.com

${ }^{4}$ Professora Dr. do Departamento de Engenharia Florestal da Universidade Estadual do Centro- Oeste- UNICENTRO, gilmaramachado@yahoo.com.br

${ }^{5}$ Acadêmico do Curso de Engenharia Ambiental na Universidade Estadual do Centro- OesteUNICENTRO, mgueri@hotmail.com

\section{Resumo}

A fabricação de papel cartão utiliza produtos de madeira, além de biomassa na forma de cavacos para geração de vapor em caldeira. O processo gera resíduos como cascas, fibras e fiapos da fabricação de pasta de madeira, lodo da estação de tratamento de efluentes (ETE), coque e coque peneirado da caldeira. O poder calorífico dos cavacos e dos resíduos foi estimado a partir de análise imediata, para avaliar o potencial de reaproveitamento energético dos resíduos na combustão em mistura com cavacos. Considerando que o poder calorífico útil (PCU) dos cavacos foi de $1917 \mathrm{kcal} / \mathrm{kg}$, analisou-se a viabilidade de secagem do lodo da ETE e das fibras e fiapos em secador de biomassa, que é possível da utilização dos gases quentes da chaminé da caldeira. Os resultados indicaram que o PCU do lodo da ETE a 55\% de umidade foi de $1729 \mathrm{kcal} / \mathrm{kg}$ e a $20 \%$ aumentaria para $3096 \mathrm{kcal} / \mathrm{kg}$. O PCU de fibras e fiapos a $80 \%$ de umidade foi de $671 \mathrm{kcal} / \mathrm{kg}$ e a $20 \%$ aumentaria para $2895 \mathrm{kcal} / \mathrm{kg}$. A determinação do poder calorífico através de análise imediata é proposta em conjunto com a prospecção de 
tecnologias disponíveis para secagem de biomassa para aumentar o poder calorífico dos resíduos.

Palavras-chave: biomassa, combustão, coprodutos

\begin{abstract}
The production of paperboard uses wood products, besides biomass as wood chips, to produce steam in the boiler. The process generates residues like bark, wood fiber and lint from the manufacture of wood pulp, sludge from the wastewater treatment plant (WWTP), coke and screened coke from the boiler. The heat values of the wood chips and residues were estimated from proximate analysis to assess the energetic potential of the residues, to be used in the combustion mixed with wood chips and bark. Whereas the low heat value (LHV) of wood chips is $1917 \mathrm{kcal} / \mathrm{kg}$, a feasibility analysis was done to dry the primary sludge and wood fiber through a biomass dryer, using the hot gases from the boiler chimmey. The results indicated that LHV of the sludge at moisture of $55 \%$ was $1729 \mathrm{kcal} / \mathrm{kg}$ and at $20 \%$ would increase to $3096 \mathrm{kcal} / \mathrm{kg}$. The LHV of the fiber and lint at moisture of $80 \%$ was $671 \mathrm{kcal} / \mathrm{kg}$, and at $20 \%$ would increase to $2895 \mathrm{kcal} / \mathrm{kg}$. The determination of the heat value from proximate analysis is proposed in conjunction with available technologies to prospect the biomass drying, to increase the heat value of the residues.
\end{abstract}

Keywords: biomass, combustion, co-products

\title{
Introdução
}

Barroso (2008) traz que o padrão energético do Brasil fundamenta-se principalmente no petróleo e na hidroeletricidade. A inevitável escassez de petróleo, um combustível não renovável, e dos impactos ambientais gerados por essas fontes de energia, torna-se necessário a busca por outras fontes para suprir a crescente demanda energética.

Como fonte energética renovável, a biomassa e seus resíduos têm se destacado no mundo inteiro. Segundo Vidal e Da Hora (2011), a biomassa pode ser definida como todo material orgânico, não fóssil, que tenha conteúdo de energia química no seu interior, o que inclui todas as vegetações aquáticas ou terrestres, árvores, biomassa virgem, lixo orgânico, resíduos de agricultura, esterco de animais e outros tipos de restos industriais. A 
biomassa de madeira inclui todo o material da árvore: tronco, ramos, folhas, casca e raízes.

Em 2013, a participação de energias renováveis na matriz energética brasileira foi de $41 \%$, mantendo-se entre as mais elevadas do mundo, enquanto que no restante do mundo em 2011 foi de apenas 13\% (MME, 2014). Em virtude do seu caráter renovável, a bioenergia tem atraído grande interesse da sociedade não apenas pela estabilidade dos preços e redução do impacto ambiental, mas por ser uma forma de energia sustentável (DRAPCHO, NHUAN e WALKER, 2008).

Quanto à produção energética, a biomassa pode ser classificada em primária, sendo proveniente de floresta ou agricultura cultivada com finalidade energética, e secundária, que são resíduos de biomassa primária, como os resíduos florestais e subprodutos de processos industriais (DRAPCHO, NHUAN e WALKER, 2008).

A biomassa celulósica residual de fábrica de papel pode ser um recurso energético potencial de baixo custo para aproveitamento energético e ao mesmo tempo para redução do impacto ambiental, uma vez que os resíduos são destinados a aterros industriais. Os principais resíduos de fábrica de papel cartão são cascas de pinus, fibra da estação de tratamento de efluentes (ETE), fibras e fiapos de madeira da fabricação de pasta mecânica, coque e coque peneirado da grelha da caldeira de biomassa.

Para a utilização desses resíduos como fonte de energia, devem-se considerar as características físicas e químicas do material, que podem influenciar no rendimento e na manutenção dos equipamentos que realizam os processos de combustão (GAVRILESCU, 2008).

Uma das pincipais propriedades dos combustívies sólidos é o poder calorífico, que é influenciado não só pela umidade, mas também pela composição elementar e também pela análise imediata.

Segundo Brand (2010), variáveis como teor de umidade e poder calorífico permitem avaliar a eficiência de biomassa como combustível.

Os resíduos de fabricação de papel contem diferentes teores de umidade e composições e uma das formas de medir o potencial de geração de energia calorífica é através da determinação do poder calorífico da biomassa residual que será utilizada na combustão.

Parikh, Channiwala e Ghosal (2005), correlacionaram o poder calorífico de vários tipos de biomassa a partir de dados da composição elementar (teor de carbono, hidrogênio, 
oxigênio, nitrogênio e enxofre) e composição imediata (teor de carbono fixo, voláteis e cinzas). O poder calorífico de maravalha de Pinus sp e de Araucaria angustifólia também foram estimados através de análise imediata e requer técnicas e equipamentos simples apresentando-se como procedimento de baixo custo operacional (MENEZES, 2013).

No presente trabalho, a análise imediata foi o método utilizado para estimar o poder calorífico de cavacos utilizados na produção de vapor, bem como das biomassas residuais do processo de fabricação de papel cartão da Ibema Cia Brasileira de Papelcartão, localizada em Faxinal da Boa Vista, Município de Turvo, no Centro-Oeste do Estado do Paraná. A fabrica tem capacidade de produção de 90 mil toneladas por ano de cartão para embalagens e o trabalho tem com o objetivo de avaliar o potencial de reaproveitamento energético de cerca de 3 mil toneladas por ano de resíduos para geração de vapor em caldeira de biomassa.

\section{Materiais e métodos}

Biomassa e resíduos celulósicos gerados no processo de fabricação de papel

A fabricação de papel cartão utiliza biomassa para produção de vapor para secagem, pela combustão de cavacos próprios (1), cavacos adquiridos de terceiros (2) e cascas de madeira (3), e gera resíduos celulósicos tais como, fibras e fiapos da fabricação de pasta de madeira (4), lodo da estação de tratamento de efluentes (ETE) (5), carvão coque (6) e carvão coque peneirado (7) da caldeira. A Figura 1 resume o processo de fabricação e indica a origem das amostras da pesquisa e foram analisadas no laboratório de Tecnologia e Utilização de Produtos Florestais da Unicentro, Campus de Irati. 


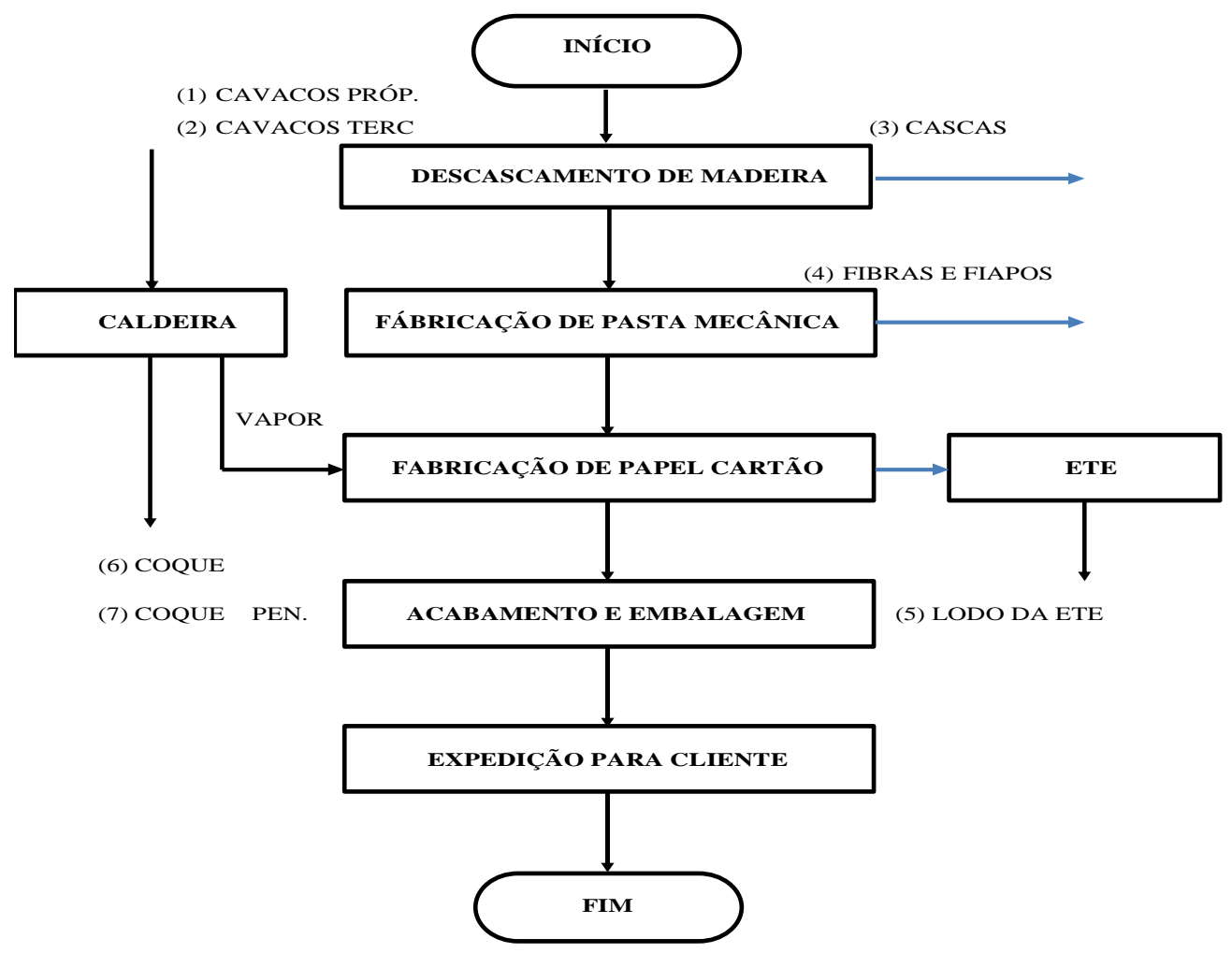

Figura 1 - Fluxograma simplificado da fabricação de papel cartão

Determinação do teor de umidade para cálculo da análise imediata em base seca

A umidade das amostras foi determinada na granulometria de 42 a 60 mesh, por secagem de aproximadamente $1 \mathrm{~g}$ de amostra na estufa a $105^{\circ} \mathrm{C}$ até massa constante, conforme Norma NBR 8112 (ABNT, 1986). Todas as análises foram feitas em triplicata e utilizou-se a Equação (1) para o cálculo da umidade percentual:

$U(\%)=[(m i-m s) / m i] \times 100$

Onde:

$\mathrm{U}(\%)$, umidade da amostra, $(\%)$

mi, massa inicial da amostra, (g)

ms, massa da amostra seca, (g).

Determinação da análise imediata

Revista Brasileira de Energias Renováveis, v. 3, p. 284- 297, 2014 
A análise imediata de um combustível, na base seca, fornece a porcentagem de material volátil, carbono fixo e cinzas As análises imediatas foram realizadas em triplicata conforme procedimento E711-87 (ASTM, 2004). O teor de voláteis é obtido após calcinação em forno mufla a $600^{\circ} \mathrm{C}$ por 10 minutos e calculado conforme Equação (2).

$\%$ Voláteis $=(\mathrm{mm}-\mathrm{mc}) \times 100 / \mathrm{mm}$

Onde:

$\mathrm{V}$, teor de voláteis, $(\%)$

mm, massa aproximada de 4,0 g da amostra antes da calcinação, (g)

mc, massa da amostra após calcinação, (g)

O teor de cinzas foi determinado pela quantificação do resíduo após pirólise a $700{ }^{\circ} \mathrm{C}$ por 6 horas, em forno mufla e calculado pela Equação (3):

$\%$ Cinzas $=100 \times(\mathrm{mr} / \mathrm{ms})$

Onde:

$\%$ Cinzas, teor de cinzas, $(\%)$;

$\mathrm{ms}$, massa aproximada de 4,0 g de amostra seca antes da pirólise, (g).

mr, massa da amostra após pirólise, (g);

O teor de carbono fixo é uma medida indireta, calculado pela Equação (4):

Carbono Fixo, $\%=100-($ Teor de cinzas em \% $)+(\%$ materiais voláteis $)$

Estimação do poder calorífico a partir da análise imediata

O poder calorífico foi estimado a partir de análise imediata pelas equações (5), (6) e (7), obtidas através de modelagem da análise imediata e do poder calorífico de diversas biomassas carbonáceas sólidas com erro absoluto de 3,74\% (PARIKH, CHANNIWALA e GHOSAL, 2005).

$P C S=84,5104 \times(\%$ carbono fixo $)+37,2601 \times(\%$ materiais voláteis $)-1,8642 \times(\%$ cinzas)

Revista Brasileira de Energias Renováveis, v. 3, p. 284- 297, 2014 


$$
P C I=P C S-(600 \times 0,09 \times \% \text { Hidrogênio })
$$

$P C U=(P C I x(1-(0,01 \times \%$ Umidade $)))-(600 x 0,01 \times \%$ Umidade $)$

Onde:

$\mathrm{PCS}^{\mathrm{s}}$, poder calorífico superior, base seca, $(\mathrm{kcal} / \mathrm{kg})$

$\mathrm{PCI}^{\mathrm{s}}$, poder calorífico inferior, base seca, $(\mathrm{kcal} / \mathrm{kg})$

$\mathrm{PCU}^{\mathrm{u}}$, poder calorífico útil, base úmida, $(\mathrm{kcal} / \mathrm{kg})$

$\mathrm{CF}$, carbono fixo, $(\%), \mathrm{V}$, teor de voláteis, $(\%), \mathrm{A}$, teor de cinzas, $(\%)$

$\mathrm{H}$, teor de Hidrogênio considerado 5,99\%

$\mathrm{U}$, teor de umidade, $(\%)$

O PCS é a quantidade de calor liberada na combustão de uma unidade de massa de combustível considerando a água de formação e água da umidade do combustível no estalo líquido, o PCI a quantidade de calor liberada sem considerar a evaporação de água de formação do combustível mais a quantidade de água da umidade do combustível (CORTEZ, LORA e GÓMEZ, 2008). O PCU é a quantidade de calor liberada útil, descontada a quantidade de calor usada para evaporar a água de formação e a umidade do combustível (BRITO, 1993).

Os coeficientes da equação 5 indicam que o teor de carbono fixo e de voláteis influenciam positivamente no poder calorífico, enquanto que o teor de cinzas influencia negativamente.

\section{Análise Estatística dos Resultados}

Utilizou-se o Minitab ${ }^{\circledR}$ para analisar os resultados através de ANOVA - Análise de Variância, pelo teste de Tukey com nível de significância de 5\% e verificar se há diferença estatística entre as médias das análises de carbono fixo, voláteis, cinzas e do poder calorífico calculado, PCS, PCI e PCU.

\section{Resultados e Discussão}

\section{Análise imediata}

Revista Brasileira de Energias Renováveis, v. 3, p. 284- 297, 2014 
Na tabela 1 são apresentados os resultados obtidos na análise imediata.

Tabela 1 - Comparação de médias da análise imediata através do teste de Tukey

\begin{tabular}{|c|c|c|c|}
\hline \multirow{2}{*}{ Material } & Carbono Fixo & Voláteis & Cinzas \\
\hline & Média (\%) & Média (\%) & Média (\%) \\
\hline (A) Cavacos próprios & $\begin{array}{l}14,8 \pm 0,23 \mathrm{e} \\
(1,56 \%)\end{array}$ & $\begin{array}{l}84,2 \pm 0,23 \mathrm{a} \\
(0,27 \%)\end{array}$ & $\begin{array}{l}1,0 \pm 0,13 \mathbf{e} \\
(12,91 \%)\end{array}$ \\
\hline (B) Cavacos de terceiros & $\begin{array}{l}25,0 \pm 0,74 \mathrm{c} \\
(2,94 \%)\end{array}$ & $\begin{array}{l}71,6 \pm 0,74 \mathrm{c} \\
(1,03 \%)\end{array}$ & $\begin{array}{l}3,4 \pm 0,27 \mathbf{d ~ e} \\
(8,00 \%)\end{array}$ \\
\hline (C) Cascas de Pinus & $\begin{array}{l}21,7 \pm 0,86 \mathbf{d} \\
(3,98 \%)\end{array}$ & $\begin{array}{l}68,1 \pm 0,86 \mathbf{d} \\
(1,27 \%)\end{array}$ & $\begin{array}{l}10,2 \pm 0,41 \mathbf{c} \\
(4,01 \%)\end{array}$ \\
\hline (D) Fibras e fiapos & $\begin{array}{l}11,5 \pm 0,61 \mathrm{f} \\
(5,29 \%)\end{array}$ & $\begin{array}{l}82,5 \pm 0,61 b \\
(0,74 \%)\end{array}$ & $\begin{array}{l}6,1 \pm 0,11 \mathbf{d} \\
(1,79 \%)\end{array}$ \\
\hline $\begin{array}{l}\text { (E) Lodo (Fibra) da } \\
\text { ETE }\end{array}$ & $\begin{array}{l}20,2 \pm 0,61 \mathbf{d} \\
(3,03 \%)\end{array}$ & $\begin{array}{l}68,3 \pm 0,61 \mathbf{d} \\
(0,90 \%)\end{array}$ & $\begin{array}{l}11,5 \pm 0,29 \mathbf{c} \\
(2,54 \%)\end{array}$ \\
\hline (F) Coque & $\begin{array}{l}58,4 \pm 0,56 \mathrm{a} \\
(0,96 \%)\end{array}$ & $\begin{array}{l}12,6 \pm 0,56 \mathrm{e} \\
(4,46 \%)\end{array}$ & $\begin{array}{l}29,0 \pm 2,65 b \\
(9,14 \%)\end{array}$ \\
\hline (G) Coque peneirado & $\begin{array}{l}50,5 \pm 0,52 b \\
(1,02 \%)\end{array}$ & $\begin{array}{l}10,0 \pm 0,52 \mathrm{f} \\
(5,16 \%)\end{array}$ & $\begin{array}{l}39,5 \pm 0,79 \mathrm{a} \\
(1,99 \%)\end{array}$ \\
\hline
\end{tabular}

Nota: No teste de Tukey, letras coincidentes indicam que as médias são iguais e letras diferentes indicam que as médias são diferentes estatisticamente, com intervalo de confiança de $95 \%(\alpha=0,05)$ e entre parênteses indica-se o coeficiente de variação (Cov).

A partir da tabela 1, percebe-se dois grupos distintos de materiais, as amostras de A a E apresentaram baixo teor de carbono fixo e de cinzas e alto teor de voláteis. As amostras $\mathrm{F}$ e $\mathrm{G}$ apresentaram baixo teor de voláteis e alto teor de carbono fixo e de cinzas. Isto pode ser explicado pelo fato do coque (F) e coque peneirado (G) serem produtos da combustão e pirólise dos cavacos na caldeira, onde houve liberação dos voláteis, a fixação do carbono e aumento do teor de cinzas, conforme observado na figura 2. 


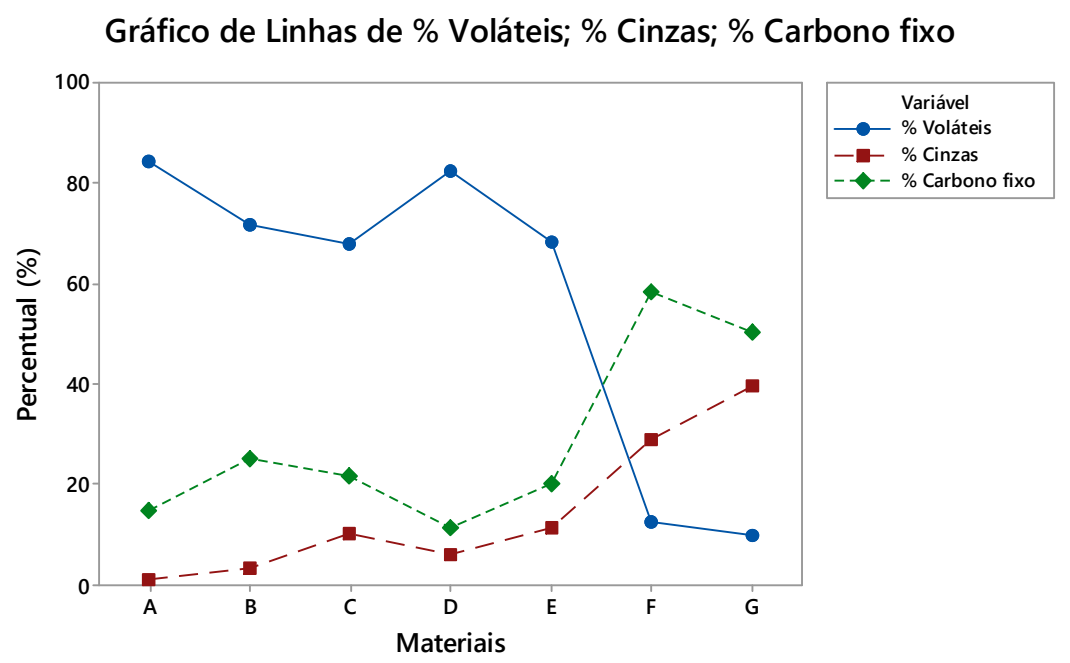

Figura 2 - Análise imediata de cavacos próprios (A), cavacos de terceiros (B), cascas (C), fibras e fiapos (D), lodo da ETE (E), coque (F) e coque peneirado (G)

Estimativa do poder calorífico superior (PCS), poder calorífico inferior (PCI) e poder calorífico útil na umidade natural (PCUum) das amostras

Através das equações 5, 6 e 7 e dos resultados de análise imediata da tabela 1, calculou-se o poder calorífico superior (PCS), o poder calorífico inferior (PCI), e o poder calorífico útil na umidade natural dos materiais antes da secagem (PCUum).

Tabela 2 - Comparação através do teste de Tukey, do poder calorífico PCS $^{\mathrm{s}}, \mathrm{PCI}^{\mathrm{s}}$ e PCUum ${ }^{\mathrm{u}}$ na umidade original, sem secagem de fibras e fiapos e lodo da ETE

\begin{tabular}{|c|c|c|c|c|}
\hline Material & Umidade (\%) & PCS (kcal/kg) & PCI (kcal/kg) & PCUum (kcal/kg) \\
\hline (A) Cavacos próprios & 55,0 & $\begin{array}{l}4387 \pm 10,9 \mathbf{c} \\
(0,25 \%)\end{array}$ & $\begin{array}{l}4064 \pm 10,9 \mathbf{c} \\
(0,27 \%)\end{array}$ & $\begin{array}{l}1758 \pm 4,9 \mathbf{d} \\
(0,28 \%)\end{array}$ \\
\hline $\begin{array}{l}\text { (B) Cavacos de } \\
\text { terceiros }\end{array}$ & 55,0 & $\begin{array}{l}4788 \pm 34,7 \mathbf{b} \\
(0,73 \%)\end{array}$ & $\begin{array}{l}4464 \pm 34,7 \mathbf{b} \\
(0,78 \%)\end{array}$ & $\begin{array}{l}1917 \pm 15,6 \mathrm{c} \\
(0,81 \%)\end{array}$ \\
\hline (C) Cascas de Pinus & 55,0 & $\begin{array}{l}4391 \pm 40,8 \mathbf{c} \\
(0,93 \%)\end{array}$ & $\begin{array}{l}4068 \pm 40,8 \mathbf{c} \\
(1,0 \%\end{array}$ & $\begin{array}{l}1730 \pm 18,35 \mathbf{d} \\
(1,06 \%)\end{array}$ \\
\hline (D) Fibras e fiapos & 80,0 & $4054 \pm 28,7 \mathrm{e}$ & $3730 \pm 26,7 \mathrm{e}$ & $671 \pm 5,74 \mathrm{e}$ \\
\hline
\end{tabular}

Revista Brasileira de Energias Renováveis, v. 3, p. 284- 297, 2014 


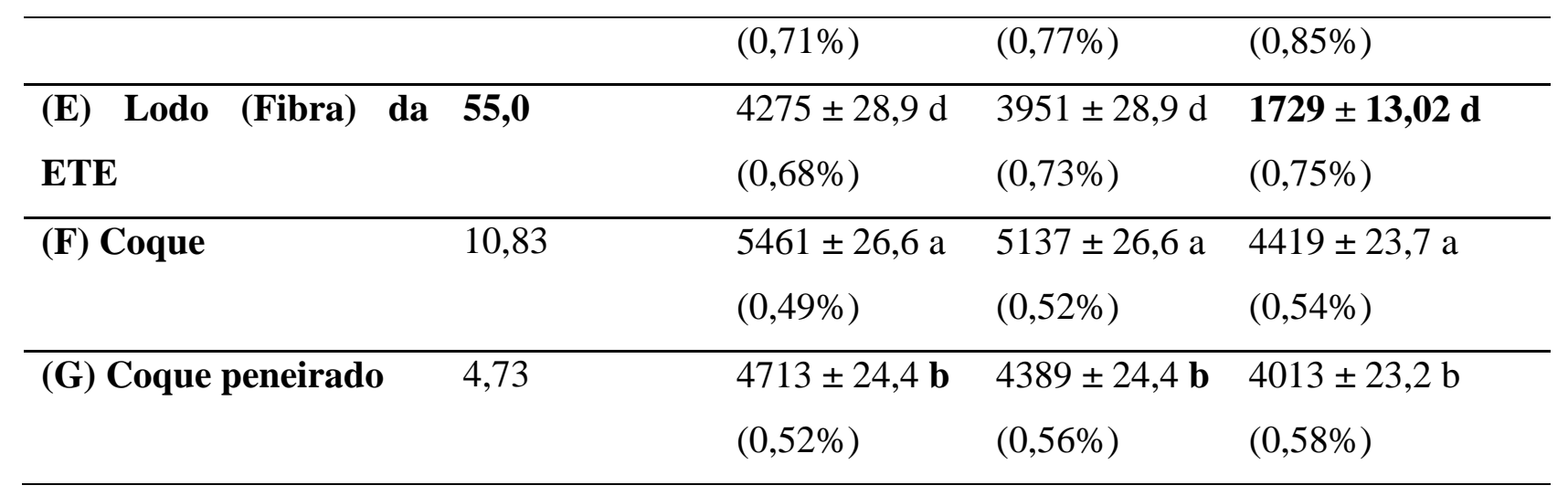

Os resultados de PCS da tabela 2 para as biomassas estudadas nesse trabalho, estão próximos dos valores obtidos por Parikh, Channiwala e Ghosal (2005), que obteve 4829 $\mathrm{kcal} / \mathrm{kg}$ para cavacos de pinus, $5308 \mathrm{kcal} / \mathrm{kg}$ para cascas de pinus, e $5901 \mathrm{kcal} / \mathrm{kg}$ para carvão de madeira de carvalho.

Uma vez que o PCU dos cavacos é $1917 \mathrm{kcal} / \mathrm{kg}$ na umidade média de 55\%, a secagem de fibras e fiapos e lodo da ETE, em secador de biomassa, com a utilização dos gases quentes da chaminé da caldeira pode ser alternativa viável para o aproveitamento energético na combustão em mistura com cavacos, uma vez que o poder calorífico destes materiais na umidade original é muito baixo.

Estimativa do poder calorífico superior (PCS), poder calorífico inferior (PCI) e poder calorífico útil após secagem (PCUsec) de fibras e fiapos, e lodo da ETE

Como os resíduos D e E apresentam alta umidade para combustão na caldeira, há necessidade de secagem através dos gases quentes de exaustão em secador rotativo ou de leito fluidizado. Sendo assim, o PCUsec destes materiais foi calculado para umidade final de $20 \%$ e estão indicados na tabela 3 .

Tabela 3 - Comparação através do teste de Tukey do poder calorífico PCS ${ }^{\mathrm{s}}, \mathrm{PCI}^{\mathrm{s}}$ e PCUsec ${ }^{\mathrm{u}}$, Revista Brasileira de Energias Renováveis, v. 3, p. 284- 297, 2014 
após secagem da fibra residual e lodo da ETE para umidade final de $20 \%$

\begin{tabular}{|c|c|c|c|c|}
\hline Material & Umidade (\%) & PCS (kcal/kg) & PCI (kcal/kg) & PCUsec (kcal/kg) \\
\hline (D) Fibras e fiapos & 20,0 & $\begin{array}{l}4054 \pm 28,7 \mathrm{a} \\
(0,71 \%)\end{array}$ & $\begin{array}{l}3730 \pm 26,7 \mathrm{a} \\
(0,77 \%)\end{array}$ & $\begin{array}{l}\mathbf{2 8 9 5} \pm \mathbf{2 2 , 9 5} \text { a } \\
(0,79 \%)\end{array}$ \\
\hline $\begin{array}{llll}\text { (E) Lodo (Fibra) da } \\
\text { ETE }\end{array}$ & 20,0 & $\begin{array}{l}4275 \pm 28,9 b \\
(0,68 \%)\end{array}$ & $\begin{array}{l}3951 \pm 28,9 b \\
(0,73 \%)\end{array}$ & $\begin{array}{l}\mathbf{3 0 9 6} \pm \mathbf{2 3 , 1 4} b \\
(0,75 \%)\end{array}$ \\
\hline
\end{tabular}

O PCU de fibras e fiapos aumentou de $671 \mathrm{kcal} / \mathrm{kg}$ para $2895 \mathrm{kcal} / \mathrm{kg}$, equivalente a um acréscimo de 331,4\% e o lodo da ETE aumentou de $1729 \mathrm{kcal} / \mathrm{kg}$ para $3096 \mathrm{kcal} / \mathrm{kg}$, equivalente a um acréscimo de 79,1\%. Estes valores de PCUsec são superiores aos de cavacos próprios, cavacos de terceiros e cascas, indicando que a secagem é viável energeticamente.

$\mathrm{Na}$ figura 3 estão representados os valores PCS, PCI, PCUum e PCUsec das biomassas e dos resíduos estudados, sendo que o aumento do poder calorífico útil de fibras e fiapos e lodo da ETE após a secagem é indicado através das flechas em vermelho.

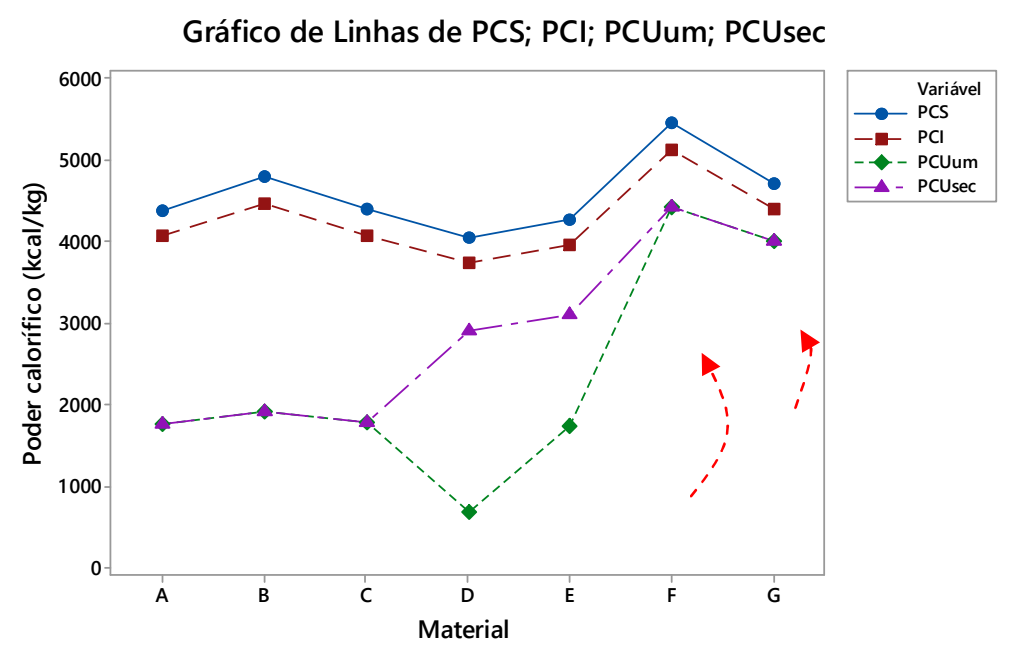

Figura 3 - Poder calorífico de cavacos próprios (A), cavacos de terceiros (B), cascas (C), fibras e fiapos (D), lodo da ETE (E), coque (F) e coque peneirado (G)

Análise de viabilidade de aproveitamento dos resíduos celulósicos na combustão 
A tabela 4 apresenta o investimento para instalação de um secador de biomassa do tipo leito fluidizado, para secagem dos resíduos celulósicos com os gases quentes da caldeira de biomassa e redução do consumo de cavacos adquiridos de terceiros.

Tabela 4 - Estimativa de investimento em secador do tipo leito fluidizado para secagem de resíduos celulósicos

\begin{tabular}{ll}
\hline Descrição & Valor (R\$) \\
\hline Custo do secador de fibras e lodo de \\
efluente (construção civil, equipamentos, $1.438 .500,00$ \\
montagem e contingências)
\end{tabular}

O custo operacional e de manutenção foi calculado em $\mathrm{R} \$ 31.938,00$ por ano, sendo $\mathrm{R} \$ 21.750,00$, referente ao custo de manutenção (1,5\% do investimento) e $\mathrm{R} \$ 10.368,00$, o custo do consumo de energia elétrica.

Tabela 5 - redução do consumo de cavacos pelo aproveitamento de resíduo celulósico seco em secador de leito fluidizado

\begin{tabular}{lll}
\hline Descrição & & Item \\
\hline $\begin{array}{l}\text { Resíduo disponível (fibras e fiapos + lodo da ETE) a 20\% } \\
\text { umidade }\end{array}$ & 0,423 \\
\hline PCUsec média de fibras e fiapos + lodo (tabela 3) & $\mathrm{kcal} / \mathrm{kg}$ & $2.995,5$ \\
\hline Calorias geradas na combustão & $\mathrm{kcal} / \mathrm{h}$ & $1.267 .096,5$ \\
\hline PCUsec cavacos (tabela 3) & $\mathrm{kcal} / \mathrm{kg}$ & 1917,0 \\
\hline Redução do consumo de cavacos com PCUsec 2.995,5 kcal/kg & $\mathrm{t} / \mathrm{h}$ & 0,660 \\
\hline Custo do cavaco & $\mathrm{R} \$ / \mathrm{t}$ & 95,00 \\
\hline Redução de custo com cavacos & $\mathrm{R} \$ / \mathrm{m}$ & $45.144,00$ \\
\hline Redução de custo com cavacos & $\mathrm{R} \$ / \mathrm{a}$ & $541.728,00$ \\
\hline
\end{tabular}

A quantidade de fibras e fiapos, e lodo da ETE é 0,423 toneladas por hora, cujo poder 
calorífico médio de $2.995,5 \mathrm{kcal}$ por $\mathrm{kg}$ e gera $1.267 .096,5 \mathrm{kcal}$ por hora. Considerando o poder calorífico dos cacavos $1.914 \mathrm{kcal}$ por $\mathrm{kg}$, o calor gerado equivale a 0,660 toneladas de cavacos por hora que serão reduzidos na alimentação da caldeira.

O cálculo do retorno do investimento é apresentado na tabela 6.

Tabela 6 - Retorno do investimento em secador de leito fluidizado

\begin{tabular}{ll}
\hline Descrição & Item \\
\hline Investimento, R\$ & $1.438 .500,00$ \\
\hline Economia líquida, R\$/ano & $541.728,00$ \\
\hline ROI, Retorno do investimento, anos & 2,65 \\
\hline
\end{tabular}

A tabela 6 indica que para um investimento em equipamento de secagem de $\mathrm{R} \$$ 1.438.500,00, o retorno do investimento é de 2,65 anos através da redução de custo de cavacos de $\mathrm{R} \$ 541.728,00$ por ano.

\section{Conclusões}

A partir dos resultados obtidos com a análise imediata para calcular o poder calorífico útil, conclui-se que o PCU de fibras e fiapos e lodo da ETE, após secagem, é maior do que o de cavacos próprios, cavacos de terceiros e cascas de pinus, demonstrando que estes resíduos podem ser aproveitados como combustível sólido na geração de calor na caldeira, desde que previamente secos em secador de biomassa.

A secagem de resíduos em secador com a utilização dos gases da caldeira, é uma alternativa viável para o aproveitamento energético do lodo da ETE e de fibras e fiapos.

\section{Agradecimentos}

Os autores agradecem a Ibema Cia. Brasileira de Papel pelo fornecimento das amostras.

\section{Referências}

Revista Brasileira de Energias Renováveis, v. 3, p. 284- 297, 2014 
AMERICAN SOCIETY FOR TESTING AND MATERIAL. E711-87: Standard test method for gross calorific value of refuse-derived fuel by the bomb calorimeter. West Conshohocken, PA, USA, 2004.

ABNT. Associação Brasileira de Normas Técnicas. NBR - 8112 (MB1857): Carvão Vegetal Análise Imediata. Outubro 1986.

BARROSO, R. A. Consumo de lenha e produção de resíduos de madeira no setor comercial e industrial do distrito federal. 2008. 65 p. Dissertação (Mestrado em Ciências Florestais), Departamento de Engenharia Florestal, Universidade de Brasília, Brasília, DF.

BRAND, M. A. Energia de biomassa florestal. Rio de Janeiro: Interciência, 2010. 114 p.

BRITO, J. O. Expressão da produção florestal em unidades energéticas. In Congresso Florestal Panamericano, 1, Congresso Florestal Brasileiro, 7, 1993, Curitiba, Anais...Curitiba: Sociedade Brasileira de Silvicultura, 1993, p. 280-282.

CORTEZ, L. A. B.; LORA, E. E. S.; GÓMEZ, E. O. Biomassa para energia. Ed. UNICAMP: Campinas, SP, 2008.

DRAPCHO, C. M.; NHUAN, N. P.; WALKER, T. H. Biodiesel engineering process technology. U.S.A.: Ed. Mc-Graw Hill, 268p., 2008. Disponível em <http://www. demec.ufmg.br/disciplinas/eng032-BL/Biodiesel_Engineering_Process_Technology.pdf> Acesso em 26 ago. 2014.

GAVRILESCU, D. Energy from biomass in pulp and paper mills. Environmental Engineering and Management Journal, v. 7, n. 5, p. 537-546. 2008.

MENEZES, M. J. S. Poder calorífico e análise imediata da maravalha de Pinus (Pinus $s p$ ) e Araucária (Araucária angustifolia) de reflorestamento como resíduos de madeira. 2013. 65 p. Dissertação (Mestrado em Energia na Agricultura). Programa de Pós-Graduação em Energia na Agricultura, UNIOESTE - Universidade do Oeste do Paraná, Cascavel, PR.

Revista Brasileira de Energias Renováveis, v. 3, p. 284- 297, 2014 
BRASIL. MME - Ministério das Minas e Energia. BEN - Balanço energético nacional 2014: ano base 2013. Empresa de Pesquisa Energética - Rio de Janeiro: EPE. 2014. 288 p.

PARIKH, J.; CHANNIWALA, S. A.; GHOSAL, G. K. A correlation for calculating HHV from proximate analysis of solid fuels. Fuel, v. 84, n. 5, p. 487-494. 2005.

VIDAL, A. C. F.; DA HORA, A. B. Perspectivas do setor de biomassa de madeira para a geração de energia. BNDES Setorial 33, Papel e Celulose, p. 261-314, 03/2011. Disponível em:

<http://www.bndes.gov.br/SiteBNDES/bndes/bndes_pt/Institucional/Publicacoes/Consulta_E xpressa/Setor/Energia/201103_08.html >. Acesso em: 30/08/2014. 